\title{
The 'Quantity' and 'Quality' of Internationalization of the Faculties in the Top Universities in China, Hong Kong, Japan, Singapore and South Korea in the Case of Economics
}

\author{
Takashi Sagara $^{1}$ \\ ${ }^{1}$ Director of Climatico Japan, Japan \\ Correspondence: Takashi Sagara, Climatico Japan, Suginami, Tokyo, Japan. Tel: 81-3-6796-9490. E-mail: \\ takashi.sagara@gmail.com
}

Received: March 3, $2014 \quad$ Accepted: March 24, $2014 \quad$ Online Published: April 13, 2014

doi:10.5430/wjss.v1n2p32 URL: http://dx.doi.org/10.5430/wjss.v1n2p32

\begin{abstract}
The 21 st century will be the glorious era of Asian universities. This positive expectation for Asian universities has been already recognized because of the current increase in the number of Asian universities in QS World University Rankings. While China, Hong Kong, Singapore and South Korea have been successful in the rankings, Japan's results have been, however, normally disappointing because Japanese universities are often very weak in one of the important ranking indicators, the international indicators. However, the International Faculty Index of the International Indicators focuses on nationalities of faculties. The paper in contrast suggests that internationalization of faculties should be measured by both the proportion of faculties who hold overseas PhDs (the 'quantity' of internationalization of faculties) and the proportion of faculties who possess PhDs from the world's best universities (the quality of internationalization of faculties), in a certain university. The 'quantity' and 'quality' of internationalization of faculties in China, Hong Kong, Japan, Singapore and South Korea are then examined in this paper in order to discover whether Japan is unsuccessful in the internationalization of its universities.
\end{abstract}

Keywords: Faculties' internationalization in the top Asian universities, QS World University Rankings, International Faculties, Economics Rankings, Competitions among the Top Asian Universities for international students

\section{Introduction}

\subsection{Asian Universities in the Current World University Rankings}

American and British universities have been dominating various kinds of world university rankings. For instance, in QS World University Rankings 2013 (Note 1), seven American universities and four British universities dominate the top 10. Moreover, there is no Asian university even, in the top 20. Asia's top university in the rankings is the National University of Singapore, who gets the 23rd place. It is apparent that it is the golden era of American and British universities.

Then, will this situation continue forever? The answer may be 'NO'. The golden era of Asian universities is expected to come in the near future. According to Ben Sowter (as cited in Yan Zang, 2013), head of QS Intelligence Unit, Asian universities have been experiencing a rapid transformation, and Singaporean, Hong Kong's, Chinese and South Korean universities, among Asian universities, are competing with the global elite universities. This positive expectation for Asian universities' dominance over global university rankings is not unrelated to the recent on-going economic development in Asia. Again, Sowter argues that because sustaining funding levels has been difficult for Western governments, the Asian universities' ability to attract the global best faculties and students has been rapidly increased.

However, as Sowter indicates, not all Asian countries but some Asian countries such as Singapore, Hong Kong, China and Korea are expected to dominate global university rankings. Indeed, in QS Asian University Rankings 2013 (Note 2), its top five universities are the Hong Kong University of Science and Technology (HKUST), Hong Kong University (HKU), the National University of Singapore (NUS), Seoul National University (SNU) and Peking University. Thus, all of the top five universities are either Singaporean, Hong Kong's, Chinese or South Korean 
universities.

Further, comparing QS Asian University Rankings 2013 with QS Asian University Rankings 2011 (Note 3), 23 universities have jumped up, including 2 Singaporean universities, 9 South Korean universities, 4 Chinese universities, 3 Hon Kong's universities, 2 Taiwanese universities, 1 Malaysian universities, 1 Japanese university and 1 Philippine university. Next, four universities have stayed in the same place: 2 Hong Kong's universities, 1 Chinese university and 1 Taiwanese university. Then, 24 universities have fallen: 1 Hong Kong's university, 12 Japanese universities, 3 Taiwanese universities, 3 Chinese universities, 3 Indian universities and 2 Thai universities. Thus, all of the Singaporean and South Korean universities have moved up. Though two of the six Hong Kong's universities, HKUST and HKU, have stayed in the same place, they have been in the 1st and 2nd places in both rankings. As for Chinese universities, though a few universities such as Peking (up from 13th to 5th) and Beijing Normal University (up from 64th to 46th), have jumped up greatly, remarkable positive/negative differences cannot be observed for other Chinese universities.

It is undoubtedly Japan that has the worst results in the comparison. While one Japanese university has moved up, the other 12 Japanese universities have fallen. In addition, the worst five universities that have dropped most in the comparison are: the University of Tsukuba (Japan) (down 11 places); Tohoku University (Japan), Keio University (Japan), Mahidol University (Thailand) (down 8 places); and Osaka University (Japan) (down 7 places). Consequently while Japanese universities are now less well-represented in Asia's university rankings, Singapore, Hong Kong and South Korea are dominating the rankings.

\subsection{Internationalization of Asian Universities}

Ince (2012) argues that the reasons for declines of Japanese universities in the rankings are due to Japan's failure in internationalization of universities. According to Ince (2012), Japanese universities are weak in the international indicators, including international faculties, international students and inbound/outbound exchange students. Regarding international faculties, the 2012 QS Asian University Rankings show that 6 Hong Kong's universities, 2 Singaporean universities and 2 Japanese universities get a 100 score in the international faculty index. While the top universities in Hong Kong and Singapore in the rankings, HKUST and NUS, are ranked 1st and 2nd respectively, Japan's top university in the rankings, the University of Tokyo, cannot be in the top 50 universities in this measurement. Indeed, while $4.5 \%$ of Tokyo's faculties are from outside Japan, $50 \%$ of HKUST's faculties are from outside Hong Kong (Ince, 2012).

In terms of international students, the Asian University Rankings demonstrate that 2 Hong Kong's universities, 2 Singaporean universities and 1 Chinese university obtain a full score. Again, while HKUST and NUS get the 1st and 2nd places, Tokyo is ranked 45th in this measurement. Additionally, though $8.3 \%$ of Tokyo's students come from outside Japan, 36.9\% of HKUST's students are from outside Hong Kong (Ince, 2012). Concerning inbound exchange students, 4 Hong Kong's universities, 1 Singaporean university and 1 Malaysian university obtain a 100 score in this measurement. HKUST and SNU again secure the 1st place and 2nd place, though Tokyo fails to be in the top 50 universities. Finally, regarding outbound exchange students, one Hong Kong's university, two Malaysian universities and one South Korean university get a full score. Though HKUST and SNU fail to be in the 1st and 2nd places, HKUST's score is 99.9 (5th) and NUS's score is 99.5 (10th). In this measurement, on the contrary, Tokyo cannot be even in the top 100 universities. Ince (2012), as a result, regards Tokyo as a place where international students are not willing to go, and whose students prefer staying at home.

\subsection{The 'Quantity' and 'Quality' of Internationalization of Faculties}

As shown above, Japanese universities have fallen in the current rankings from the previous rankings because they have failed to be 'internationalized'. However, it is doubtful that the QS Asian University Rankings appropriately deal with the degrees of internationalization of faculties in universities. In the rankings, universities with more foreign faculties are better scored. However, suppose that there are A university and B university in a country: all of A's faculties are from outside the country, but hold PhDs from A University, while all of B's faculties come from the country and hold PhDs from B University. Some may argue that faculties of A University are more internationalized because of nationalities of faculties. However, it should be more appropriate to consider that faculties of both universities are not internationalized because they are similarly educated and granted $\mathrm{PhDs}$ from the institutes of the country. Thus, it can be more important to investigate the proportion of faculties in a university whose PhDs are granted by overseas institutes, rather than focusing on nationalities of faculties, in order to measure the 'quantity' of internationalization of faculties in a university. Surely, if the proportion in a university is high, it can then be supposed that faculties of the university are internationalized in terms of 'quantity'. 
Increasing the 'quantity' of internationalization of faculties in a university can be easy because there are approximately 200 countries and more than 20,000 universities in the world (Note 4). As indicated at the beginning of this paper, however, the world's top 10 universities are dominated by the prestigious American and British institutes based on QS World University Rankings 2013. Further, according to the rankings, the global top 50 universities are comprised by universities of only 13 countries: including US (20), UK (8), Australia (4), Canada (3), Hong Kong (3), Switzerland (2), Singapore (2), France (2), Japan (2), Canada (2), South Korea (1), Denmark (1) and Germany (1).

Thus, it is important to examine the 'quality' of internationalisation of faculties in a university as well as the 'quantity'. The 'quality' of internationalization of faculties in a university can be assessed by the measurement of the proportion of faculties who hold PhDs from the world's best universities. The 'high-quality' internationalization of faculties in a university can then be defined as keeping high the proportion of faculties with PhDs from the world's top institutes, no matter what countries their PhD-granting institutes are, domestic or overseas (see Salmi, 2009). Finally, this study focuses on the internationalization of faculties in economics. This subject's focus is necessary because the world's top universities are different in subjects. For instance, according to QS World University Rankings by Subject 2013, the top five universities in Accounting \& Finance are Harvard University, the London School of Economics (LSE), the University of Oxford, the University of Cambridge and the Massachusetts Institute of Technology (MIT) (Note 5). However, those in Agriculture \& Forestry are the University of California-Davis, Wageningen University, Cornell University, the University of Wisconsin-Madison and Texas A\&M University.

This paper then examines both the proportion of faculties who hold overseas PhDs in universities of China, Hong Kong, Japan, Singapore and South Korea and that of faculties with PhDs from the world's best institutes in their universities, in the field of economics. Further, the examination of the 'quantity' and 'quality' of internationalization of faculties in each country are also carried out to understand its characteristics in the internationalization of faculties. After the examination, this study discovers that the top universities in Hong Kong, Singapore and South Korea are at the forefront of Asian universities in terms of both 'quantity' and 'quality', while the top Chinese and Japanese universities are poorly internationalized in both senses. It similarly finds that the 'quantity' and the 'quality' of internationalization of faculties in Hong Kong, Singapore and South Korea are remarkable, though those of China and Japan are not satisfactory.

\subsection{Internationalization of Universities}

Before moving to the next section, it should be necessary to discuss internationalization of universities because it is the main theme of this study. As internationalization is used as a key indicator in QS University Rankings, it has been widely recognized that internationalization of universities is regarded as important as teaching, research and employability of universities. Knight (2003) argues that internationalization of universities can be defined as the process of incorporating global, intercultural or international dimension into the functions, objective, or delivery of university education.

Internationalization of universities is seen as necessary for universities because of a wide range of benefits that it is expected to bring about. According to Simmons (2014, March 11), there are four kinds of benefits of university internationalization. Thorough internationalization of universities, students can deepen the understanding of global issues and their local impacts; they can obtain skills that enable them to move in heterogeneous environments with a wide range of people; they can respect differences/different values and recognize different cultures as legitimate; and they can advance and handle intercultural communication skills. Surely, such an internationalized university can attract both students and academics from around the world (Top Universities, 2011 August 5).

Though Japanese universities are very poorly evaluated in terms of internationalization, Japan's Government also strongly recognises the benefits of university internationalization and acknowledges that internationalization of universities is thus significant challenges for its universities (Ministry of Education, Culture, Sports, Science and Technology Japan [MEXT], 2008). According to MEXT (2008), internationalization of universities is essential for Japan because high-level education and research can be carried out by gathering researchers and students from both inside the country and abroad. Further, MEXT argues that Japanese people who can internationally succeed will not be developed without internationalization of universities.

In order to internationalize universities, universities can take their own approaches because internationalization of universities, as Knight (2003) indicates, does not mean a single specific task for universities. Increasing the proportion of both international students and faculties may be a common approach for internationalization. Increasing both the number and proportion of 'global' courses and those of faculties who are engaged in an international partnership are identified as approaches for internationalization by Morris (2009). Simmons (2014, 
March 11) specifies a less academic approach for internationalization, campus globalization, by, for example, nurturing a campus environment that encourages respect for diversity, responsible citizenship and integrity. Increasing the 'quantity' and the 'quality' of internationalization of faculties that this study considers as a significant internationalization indicator can be also recognized as approaches for university internationalization.

\section{Method}

\subsection{Sampling Procedures}

Regarding the 'quantity' and 'quality' of internationalization of faculties in each university, this study investigated the 'quantity' and 'quality' of internationalization of faculties of Chinese, Hong Kong's, Japanese, Singaporean and South Korean universities that were in the top 100 Asian universities based on the QS Asian University Ranking 2011, in terms of economics. The total number of them was 58: including 18 Chinese universities, 6 Hong Kong's universities, 17 Japanese universities, 3 Singaporean universities and 14 South Korean universities. Searching for the $\mathrm{PhD}$-granting institutions of faculties, conducted from June to July in 2011, was solely dependent on the websites of the 58 universities. Then, 22 universities were excluded from this research because they did not have English pages, economics schools, information on the PhD-granting institutions of faculties or even accessible web pages: 22 universities were comprised by 10 Chinese universities, 4 Japanese universities, 7 South Korean universities, and 1 Hong Kong's university. 36 universities were consequently evaluated in this research.

\subsection{Measuring the 'Quantity' and 'Quality' of Internationalization of Faculties}

In order to measure the proportion of faculties with overseas $\mathrm{PhDs}$ in the top universities of these countries, to disclose the 'quantity' of internationalization of faculties, this research simply makes the number of faculties who hold overseas PhDs divided by the total number of PhD faculties, in each university. While the measurement of the 'quantity' of internationalization of faculties is simple and straight-forward, that of the 'quality' of internationalization of faculties may be relatively complicated. In order to measure the 'quality', this research at first allocated points (1-50) to the top 50 universities based on the QS World University Rankings by Subject 2011 Economics and Econometrics (Note 7): Harvard, top in the rankings, was allocated 50 points, MIT (2nd) was 49 points, Stanford University (3rd) was 48 points, LSE (4th) was 47 points, Oxford (5th) was 46 points and so forth. Then, a faculty can earn points where he/she holds a $\mathrm{PhD}$ from one of the top 50 universities in economics. 50 points are for instance given to a faculty who holds a PhD from Harvard. A faculty who does not possess a PhD from one of the world's top 50 universities scores zero. Then, by adding points achieved by all faculties in a university, the study gained the total number of points in a university. Next, the total number of points was divided by the number of PhD faculties in a university and the average points per faculty were acquired. The average points per faculty are used in this research to measure the 'quality' of internationalization of faculties.

However, it can be criticized that a university with the smaller number of faculties can be inadequately too much evaluated in this way: for instance, if a university has only one faculty, but he/she holds a $\mathrm{PhD}$ from Harvard, then its average points per faculty become 50 . As it seems inappropriate, universities which have more than $20 \mathrm{PhD}$ faculties, namely 22 of the 36 universities, are assessed in the measurement of the 'quality' of internationalization of universities.

Regarding the measurement of the internationalization of faculties in each university, it should be mentioned that a number of faculties in some of the 36 universities were not assessed because their PhD-granting institutions were unknown from their websites. The top university in Japan, Tokyo University, was as a result excluded from the measurement of the quality of internationalization as only 10 of 59 faculties in Tokyo provided the information on their $\mathrm{PhD}$-granting institutions. However, the provision of faculties' profiles such as their PhD-granting institutions and research activities on websites in English must be essential for the internationalization of universities (Dill \& Soo, 2004). Indeed, although there are a few exceptions, the top American and British universities always provide the information on PhD-granting institutions of all faculties on their websites. Moreover, among the three Singaporean universities, while the profiles of all faculties in Singapore Management University and the National University of Singapore were provided on the websites, those of 26 out of the 27 faculties in Nanyang University were available on the website. However, because some of the top universities in the other countries, especially China and Japan, did not provide the information on profiles of faculties such as their PhD-granting institutions on the websites, they should be improved as soon as possible (see Salmi, 2009).

As far as the 'quantity' and 'quality' of internationalization of faculties in each country are concerned, this study similarly examined both the national proportion of faculties who hold PhDs from foreign countries (the total number 
of faculties with overseas PhDs from in the assessed universities in a country divided by the total number of all $\mathrm{PhD}$ faculties in the assessed universities in the country) and the national average points per faculty in each country (the total number of points earned by all $\mathrm{PhD}$ faculties in the assessed universities in a country divided by the total number of all $\mathrm{PhD}$ faculties in the assessed universities in the country).

\section{Results}

\subsection{The Proportion of Faculties with Foreign PhDs in Each University}

As discussed above, to secure the high 'quantity' of internationalization of faculties, the proportion of faculties with overseas PhDs in a university should be high. Then, as shown in Table 1, the top ten universities in this measurement are all South Korean, Hong Kong's and Singaporean. Hong Kong's universities in the top ten include the Hong Kong University of Science and Technology (HKUST) (100\%, equal 1st), Hong Kong University (HKU) (97\%, equal 4th), the City University of Hong Kong (96\%, equal 7th) and the Chinese University of Hong Kong (CUHK) (94\%, 9th); Singaporean universities in the top ten are Singapore Management University (SMU) (97\%, equal 4th) and Nanyang University $(88 \%, 10$ th); and South Korean universities in the top ten are comprised by Sogang University $(100 \%$, equal 1st), Sungkyunkwan University (SKU) (0\%, equal 1st), Seoul National University (SNU) (97\%, equal 4th) and Yonsei University (96\%, equal 7 th).

The bottom ten universities in this measurement are contrarily comprised by eight Japanese universities and two Chinese universities. Though more than $90 \%$ of the faculties in the top nine universities hold PhDs from the same universities, less than $40 \%$ of the faculties in the bottom 8 universities hold overseas PhDs.

Table 1. The Proportion of Faculties with Overseas PhDs

\begin{tabular}{cccc}
\hline Ranking & University & Country & Proportion \\
\hline 1 & HKUST & HK & $100 \%$ \\
1 & Sogang & KR & $100 \%$ \\
1 & SKU & KR & $100 \%$ \\
4 & HKU & HK & $97 \%$ \\
4 & SNU & KR & $97 \%$ \\
4 & SMU & SG & $97 \%$ \\
7 & City & HK & $96 \%$ \\
7 & Yonsei & KR & $96 \%$ \\
9 & CUHK & HK & $94 \%$ \\
10 & Nanyang & SG & $88 \%$ \\
11 & Xiamen & CN & $83 \%$ \\
12 & Tsinghua & CN & $79 \%$ \\
13 & HBU & JP & $65 \%$ \\
14 & Hokkaido & JP & $40 \%$ \\
15 & Peking & CN & $39 \%$ \\
16 & Waseda & JP & $30 \%$ \\
16 & Yokohama & JP & $30 \%$ \\
18 & Kyoto & JP & $29 \%$ \\
19 & Doshisha & JP & $27 \%$ \\
20 & RMU & JP & $21 \%$ \\
21 & Tohoku & JP & $19 \%$ \\
22 & Shandong & CN & $11 \%$ \\
\hline
\end{tabular}

\subsection{Average Points per Faculty in Each University}

In terms of university's average points per faculty, as demonstrated in Table 2, the university that achieves the highest points is $\mathrm{SNU}$ (30.59). There are $37 \mathrm{PhD}$ faculties with $54 \%$ of them from the world top 10 universities, $14 \%$ 
from the top 11-20,5\% from the top 21-30 and 5\% from the top 41-50. SMU obtains the second highest points (29.89). The university has $38 \mathrm{PhD}$ faculties, with $45 \%$ from the top $10,26 \%$ from the top $11-20,5 \%$ from the top 21-30 and 5 from the top 31-40.

HKUST obtains the third highest points of 24.91 . HKUST has $23 \mathrm{PhD}$ faculties: $35 \%$ from the top $10,13 \%$ from the top $11-20,13 \%$ from the top $21-30$ and $9 \%$ from the top 31-40. Yonsei is the fourth best with the average points of 22.29. Yonsei has $28 \mathrm{PhD}$ faculties, and $39 \%$ of them hold $\mathrm{PhDs}$ from the top $10,18 \%$ from the top $11-20,7 \%$ from the top 21-30 and 14\% from the top 31-40. Sogang then follows Yonsei with the average points of 21.69. The university has $26 \mathrm{PhD}$ faculties, including $31 \%$ from the top $10,12 \%$ from the top $11-20,8 \%$ from the top $21-30$ and $12 \%$ from the top $31-40$.

HKU comes sixth with the average points of 18.94 . There are $34 \mathrm{PhD}$ faculties: $24 \%$ from the top $10,9 \%$ from the top $11-20,18 \%$ from the top $21-30$ and $9 \%$ from the top $41-50$. The seventh is CUHK with the average points of 18.8 . There are $31 \mathrm{PhD}$ faculties in the university: $26 \%$ from the top 10, 10\% from the top $11-20,10 \%$ from the top 30, 3\% from the top 31-40 and 3\% from the top 41-50. Hitotsubashi University of Japan (HBU) achieves the eighth highest points of 18.2. Among its $48 \mathrm{PhD}$ faculties, $19 \%$ of them hold $\mathrm{PhDs}$ from the top 10, $8 \%$ from the top 11-20, $21 \%$ from the top $21-30,21 \%$ from the top 31-40 and 4\% from the top 41-50. SKU has the ninth highest points of 17.39 . The university has $23 \mathrm{PhD}$ faculties: $30 \%$ from the top 10, 9\% from the top 11-20, 17\% from the top 31-40 and $4 \%$ from the top 41-50. Nanyang is the tenth with the average points of 16.03 . Nanyang has $26 \mathrm{PhD}$ faculties with $15 \%$ from the top $10,15 \%$ from the top $11-20,8 \%$ from the top $31-40$ and $4 \%$ from the top $41-50$.

Regarding the bottom ten universities, there are six Japanese universities, three Chinese universities and one Hong Kong's university. The bottom universities are thus dominated by Japanese and Chinese universities. Contrarily, South Korean, Hong Kong's and Singaporean universities dominate the top ten, with four places for South Korea, three for Hong Kong and two for Singapore.

Table 2. Average Points per Faculty (APF) and PhD-granting Institutions' Ranking

\begin{tabular}{ccccccccc}
\hline Ranking & University & Country & APF & $1-10$ & $11-20$ & $21-30$ & $31-40$ & $41-50$ \\
\hline 1 & SNU & KR & 30.59 & $54 \%$ & $14 \%$ & $5 \%$ & $0 \%$ & $5 \%$ \\
2 & SMU & SG & 29.89 & $45 \%$ & $26 \%$ & $5 \%$ & $5 \%$ & $0 \%$ \\
3 & HKUST & HK & 24.91 & $35 \%$ & $13 \%$ & $13 \%$ & $9 \%$ & $0 \%$ \\
4 & Yonsei & KR & 22.29 & $39 \%$ & $18 \%$ & $7 \%$ & $14 \%$ & $0 \%$ \\
5 & Sogang & KR & 21.69 & $31 \%$ & $12 \%$ & $8 \%$ & $12 \%$ & $0 \%$ \\
6 & HKU & HK & 18.94 & $24 \%$ & $9 \%$ & $18 \%$ & $0 \%$ & $9 \%$ \\
7 & CUHK & HK & 18.8 & $26 \%$ & $10 \%$ & $10 \%$ & $3 \%$ & $3 \%$ \\
8 & HBU & JP & 18.2 & $19 \%$ & $8 \%$ & $21 \%$ & $4 \%$ & $4 \%$ \\
9 & SKU & KR & 17.39 & $30 \%$ & $9 \%$ & $0 \%$ & $17 \%$ & $4 \%$ \\
10 & Nanyang & SG & 16.03 & $15 \%$ & $15 \%$ & $8 \%$ & $12 \%$ & $4 \%$ \\
11 & Tsinghua & CN & 12.78 & $11 \%$ & $11 \%$ & $0 \%$ & $14 \%$ & $11 \%$ \\
12 & Yokohama & JP & 12.34 & $9 \%$ & $4 \%$ & $26 \%$ & $0 \%$ & $0 \%$ \\
13 & Peking & CN & 11.66 & $4 \%$ & $2 \%$ & $2 \%$ & $49 \%$ & $4 \%$ \\
14 & City & HK & 7.7 & $4 \%$ & $4 \%$ & $4 \%$ & $17 \%$ & $13 \%$ \\
15 & Xiamen & CN & 7.68 & $4 \%$ & $2 \%$ & $13 \%$ & $9 \%$ & $11 \%$ \\
16 & Kyoto & JP & 7.64 & $13 \%$ & $3 \%$ & $3 \%$ & $0 \%$ & $0 \%$ \\
17 & Tohoku & JP & 7.34 & $4 \%$ & $0 \%$ & $23 \%$ & $0 \%$ & $0 \%$ \\
18 & Waseda & JP & 6.37 & $9 \%$ & $0 \%$ & $9 \%$ & $3 \%$ & $0 \%$ \\
19 & Hokkaido & JP & 5.71 & $3 \%$ & $3 \%$ & $14 \%$ & $0 \%$ & $0 \%$ \\
20 & Doshisha & JP & 4.84 & $3 \%$ & $3 \%$ & $9 \%$ & $0 \%$ & $3 \%$ \\
21 & RMU & JP & 3.5 & $0 \%$ & $0 \%$ & $7 \%$ & $11 \%$ & $0 \%$ \\
22 & Shandong & CN & 0 & $0 \%$ & $0 \%$ & $0 \%$ & $0 \%$ & $0 \%$ \\
\hline
\end{tabular}




\subsection{The National Proportion of Faculties with Foreign PhDs}

As far as the national proportion of faculties who hold overseas PhDs, as displayed in Table 3, Hong Kong has the highest proportion of the faculties with foreign PhDs (97\%). Because the proportion of South Korea is $96 \%$ and that of Singapore is $95 \%$, more than 90 percent of the faculties in the top universities of these three countries hold $\mathrm{PhDs}$ from outside their countries. Contrarily, $46 \%$ of the faculties in the top universities in China and $37 \%$ in Japan hold $\mathrm{PhDs}$ from foreign countries.

\subsection{The National Average Points per Faculty}

As it is also presented in Table 3, South Korea has the highest national average points per faculty (24.2) with 34\% of its faculties from the top 10, $16 \%$ from the top $11-20,5 \%$ from the top $21-30,11 \%$ from the top $31-40$ and $5 \%$ from the top 41-50. Singapore comes second with the national average points of 23.2 with $28 \%$ from the top $10,20 \%$ from the top $11-20,9 \%$ from the top $21-30,7 \%$ from the top $31-40$ and $1 \%$ from the top $41-50$. Then, Hong Kong secures the third place with the average points of 20 with $21 \%$ from the top $10,8 \%$ from the top $11-20,11 \%$ from the top $21-30,7 \%$ from the top $31-40$ and $6 \%$ from the top $41-50$. While all of the top three countries have more than 20 points, the bottom two countries, namely China and Japan, obtain less than 10 points. Japan is the fourth with the national average points of 9.7 with $9 \%$ from the top $10,4 \%$ from the top $11-20,16 \%$ from the top $21-30,3 \%$ from the top $31-40$ and $1 \%$ from the top $41-50$. China has the lowest national average points per faculty (6.9) with $4 \%$ from the top $10,3 \%$ from the top $11-20,3 \%$ from the top $21-30,16 \%$ from the top $31-40$ and $5 \%$ from the top $41-50$.

Table 3. The National Proportion of Faculties with Domestic PhDs, Average Points per Faculty (APF) and PhD-granting Institutions' Ranking

\begin{tabular}{cccccccc}
\hline & $\begin{array}{c}\text { overseas } \\
\text { PhD }\end{array}$ & & & Top & Top & Top & Top \\
Country & proportion & APF & Top 1-10 & $11-20$ & $21-30$ & $31-40$ & $41-50$ \\
\hline HK & $97 \%$ & 20 & $21 \%$ & $8 \%$ & $11 \%$ & $7 \%$ & $6 \%$ \\
KR & $96 \%$ & 24.2 & $34 \%$ & $16 \%$ & $5 \%$ & $11 \%$ & $5 \%$ \\
SG & $95 \%$ & 23.2 & $28 \%$ & $20 \%$ & $9 \%$ & $7 \%$ & $1 \%$ \\
CN & $46 \%$ & 6.9 & $4 \%$ & $3 \%$ & $3 \%$ & $16 \%$ & $5 \%$ \\
JP & $37 \%$ & 9.7 & $9 \%$ & $4 \%$ & $16 \%$ & $3 \%$ & $1 \%$ \\
\hline
\end{tabular}

\section{Discussion}

The previous section demonstrated the proportion of faculties with foreign PhDs and the university's average points per faculty in each university and each country. Then, this section examines in detail the results to discover the 'quantity' and 'quality' of internationalization of the faculties in the top universities in China, Hong Kong, Japan, Singapore and South Korea.

\subsection{The 'Quantity' and 'Quality' of Internationalization of Faculties in Each University}

HKUST, Sogang, SKU, HKU, SNU, SMU, City, Yonsei and CUHK are highly internationalized in terms of the 'quantity' of internationalization of faculties. Especially, it is amazing that all of the faculties in HKUST, Sogang and SKU hold PhDs from outside their countries. In contrast, it seems that some universities are not interested in the internationalization of faculties. For instance, almost $90 \%$ of the faculties in Shandong University and nearly $80 \%$ of the faculties in Tohoku University and Ritsumeikan University (RMU) hold domestic PhDs. Thus, there are huge differences among the Asian universities in terms of the 'quantity' of internationalization of faculties. In addition, there are distinctive differences between the universities of Hong Kong, Singapore and South Korea, and those of China and Japan. The top ten universities in the proportion of faculties who hold overseas PhDs are all Hong Kong's, Singaporean and South Korea universities. Contrarily, the rest of the universities are all Chinese and Japanese. Though most of the Chinese and Japanese universities are severely less internationalization in 'quantity', a few are relatively successful among them: Xiamen University, Tsinghua University and HBU make the holders of domestic $\mathrm{PhDs}$ less than $40 \%$.

As far as the 'quality' of internationalization, according to the average points per faculty, the quality of internationalization of faculties is highest in SNU and SMU. Their average points are 30.59 and 29.89: 54\% of the $\mathrm{PhD}$ faculties in SNU and 45\% in SMU hold PhDs from the top 10; 68\% in SNU and 71\% in SMU from the top 20; 
further, $78 \%$ in SNU and $82 \%$ in SMU from the top 50. HKUST, Yonsei and Sogang are also greatly internationalized in term of 'quality', as all of them have more than twenty average points. Indeed, the faculties in these universities are dominated by the holders of PhDs from the top 50 universities: $35 \%$ of its faculties in HKUST, $39 \%$ in Yonsei and 31\% in Sogang hold PhDs from the top 10; 48\% in HKUST, 57\% in Yonsei and 42\% in Sogang hold PhDs from the top 20; 70\% in HKUST, 79\% in Yonsei and 62\% in Sogang possess PhDs from the top 50.

While the universities that are highly internationalized in 'quality' are mostly dominated by those of Hong Kong, Singapore and South Korea, the universities with the 'low-quality' internationalization are largely occupied by the Chinese and Japanese universities: though the 'quality' of internationalization of the HBU's faculties is sufficiently high (18.2) and that of the City's faculties is low (7.7).

In addition, the top three universities, namely SNU, SMU and HKUST, seem highly motivated to employ faculties from the best of the best universities. In these universities, the proportion of faculties from the top 10 is the highest, that of the faculties from the top 11-20 is the second highest, that of the faculties from the top 21-30 is the third highest and so forth.

Further, the proportion of faculties who hold PhDs from the top 10 is highest in all of the Hong Kong's, Singaporean and South Korean universities, except City: that of those from the top 31-40 is the highest in City. On the contrary, the proportion of $\mathrm{PhD}$ faculties from the top 21-30 is highest in six of the eight Japanese universities: though that of those from the top 10 is highest in Kyoto; that of those from the top 31-40 is highest in RMU; and the proportion of those from the top 21-30 in Waseda is the same as that of those from the top 10. In addition, the proportion of faculties from the top 31-40 is highest in two of the four Chinese universities, Peking and Tsinghua: that of faculties from the top 21-30 is, however, highest in Xiamen, and Shandong does not have faculties from the global top universities.

These results may be mainly due to the dominance of their most prestigious universities, Tokyo (top 21-30 in the world) and Peking (top 31-40), over the university education and research in both countries. They are recognized as not only top in their countries but some of the best universities in Asia and even in the world. It is thus understandable that universities in both countries employ faculties who hold PhDs from Tokyo and Peking without being highly motivated to obtain faculties from the top 10/20 universities in the world. It may be possible for both Chinese and Japanese universities to improve the average points per faculty or the 'quality' of internationalization of faculties if Tokyo and Peking can become the top 10/20 universities in the world. However, such an 'easy-peasy' strategy of them may be dangerous because there is a possibility that Tokyo and Peking cannot improve their positions in the global university competitions, which will result in the lower 'quality' of internationalization of their universities. In addition, at least, the 'quantity' of internationalization of the Chinese and Japanese universities will not be improved by the strategy.

In terms of both the 'quantity' and the 'quality' of internationalization of faculties, there are small differences between the ranking of the universities in the 'quantity' of internationalization of faculties and the ranking of those in the 'quantity' of internationalization of faculties. Most of the universities move up/down by a few places, but a few jump up/fall by five places or above. SKU, City and Hokkaido University, for example, fall substantially: SKU (equal 1st in the 'quantity' ranking to 9th in the 'quality' ranking), City (equal 7th to 14th) and Hokkaido (14th to 19th). Contrarily, HBU jumps up from 13th in the quantity ranking to 8th in the 'quality' ranking. Thus, although SKU and City are highly internationalized in terms of 'quantity', the 'quality' of internationalization of their faculties is not so remarkable. It can then be concluded that the faculties of HKUST, Sogang, HKU, SNU, SMU, Yonsei, CUHK and Nanyang are most internationalized in terms of both 'quantity' and 'quality'.

\subsection{Statistical Analysis of the Relationship between the 'Quantity' and the 'Quality'}

As shown above, there are small differences between these two rankings. Then, the relationship between these two rankings should be statistically analyzed in order to understand the relationship between them in more detail. The Spearman's rank correlation coefficient can be useful to measure the strength of the association between two variables (the 'quantity' of internationalization of faculties, $X$, and the 'quality' of internationalization of faculties, $Y$ ). It can assess how well the relationship between two variables can be described by an arbitrary monotonic function, and it is unnecessary to make any assumptions about the frequency distribution of the variables. (Hauke \& Kossowski, 2011). The technique can be applied when the variables are not normally distributed and interval or the sample size is small.

The Spearman rank correlation coefficient is calculated according to the following equitation when ties are involved: 


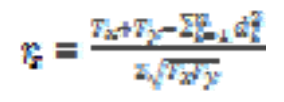

where $n$ is the number of data pairs and $d_{i}$ is the difference between ranks for each $x_{i}$ and $y_{i}$ and

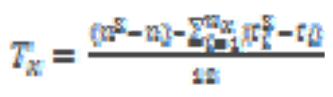

and

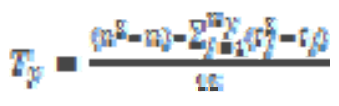

where $n_{x}$ and $n_{y}$ are the numbers of tied groups and $t_{i}$ and $t_{j}$ are the numbers of tied data in the ith and jth group.

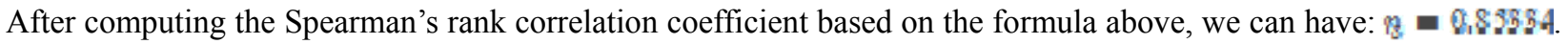
In order to test if the calculated value of 0.85334 is significant at the $95 \%$ probability level, we need to compare that value to the critical value: critical $\mathrm{p}(\mathrm{n}=22, \alpha=0.05)=0.426$. Because the calculated value exceeds the critical value, we can conclude that there is a rank order relationship between the 'quantity' and the 'quality' of internationalization of faculties in universities. Further, considering the calculated value of 0.85334 , it can be expected that the relationship is very strong. The strong relationship between the 'quantity' and the 'quality' of internationalizations of faculties in universities can be also visually recognized in the scattergram as demonstrated in Figure 1. Thus, it can be strongly assumed that a university that is more highly internationalized by 'quantity' tends to be better internationalized by 'quality' in this case study.

\subsection{The 'Quantity' and 'Quality' of Internationalization of Faculties in Each Country}

In this section, the 'quantity' and the 'quality' of internationalization of faculties in each country are examined. Following the conclusion above, it can be easily supposed that the faculties in Hong Kong, Singapore and South Korea are highly internationalized in both senses because all of the most internationalized universities above are all those of Hong Kong, Singapore and South Korea. This supposition is true, and there is no surprise at all.

Regarding the 'quantity' of internationalization, $97 \%$ of the faculties in the top universities in Hong Kong, 96\% in South Korea and $95 \%$ in Singapore hold overseas PhDs. Nearly $95 \%$ of the faculties in these three countries thus possess $\mathrm{PhDs}$ from foreign countries. In contrast, $46 \%$ in China and 37\% in Japan hold overseas PhDs, meaning that more than half of the faculties in both countries hold domestic PhDs.

The 'quality' of internationalization of the faculties in Hong Kong, Singapore and South Korea is also high. Especially, the faculties in Singapore and South Korea are amazingly high because the average points per faculty in both countries are respectively 24.2 and 23.2, while those in Hong Kong are 20.

Further, 34\% of the faculties in South Korea, 28\% in Singapore and 21\% in Hong Kong hold PhDs from the world's top 10 universities; $50 \%$ in South Korea, $48 \%$ in Singapore and 29\% in Hong Kong from the top 20; and 71\% in South Korea, $65 \%$ in Singapore and 53\% in Hong Kong from the top 50.

On the contrary, the 'quality' of internationalization of the faculties in Japan and China is regrettably low. The average points per faculty of Japan and China are respectively 9.7 and 6.9. In addition, mainly because of Tokyo and Peking, as discussed above, the proportion of the faculties who hold PhDs from the top 21-30 is highest in Japan (16\%) and that of those from the top 31-40 is highest in China (16\%). Moreover, $9 \%$ of the faculties in Japan and 4\% in China hold PhDs from the top 10; 13\% in Japan and 7\% in China from the top 20; and 33\% in Japan and 31\% in China from the top 50 .

Hence, though more than half of the faculties in Singapore, South Korea and Hong Kong hold PhDs from the top 50 universities, less than 35\% in Japan and China are the holders of PhDs from the top 50 universities. The 'quantity' and the 'quality' of internationalization of the faculties in Hong Kong, Singapore and South Korea are therefore magnificent, while those in Japan and China are rather disappointing. 


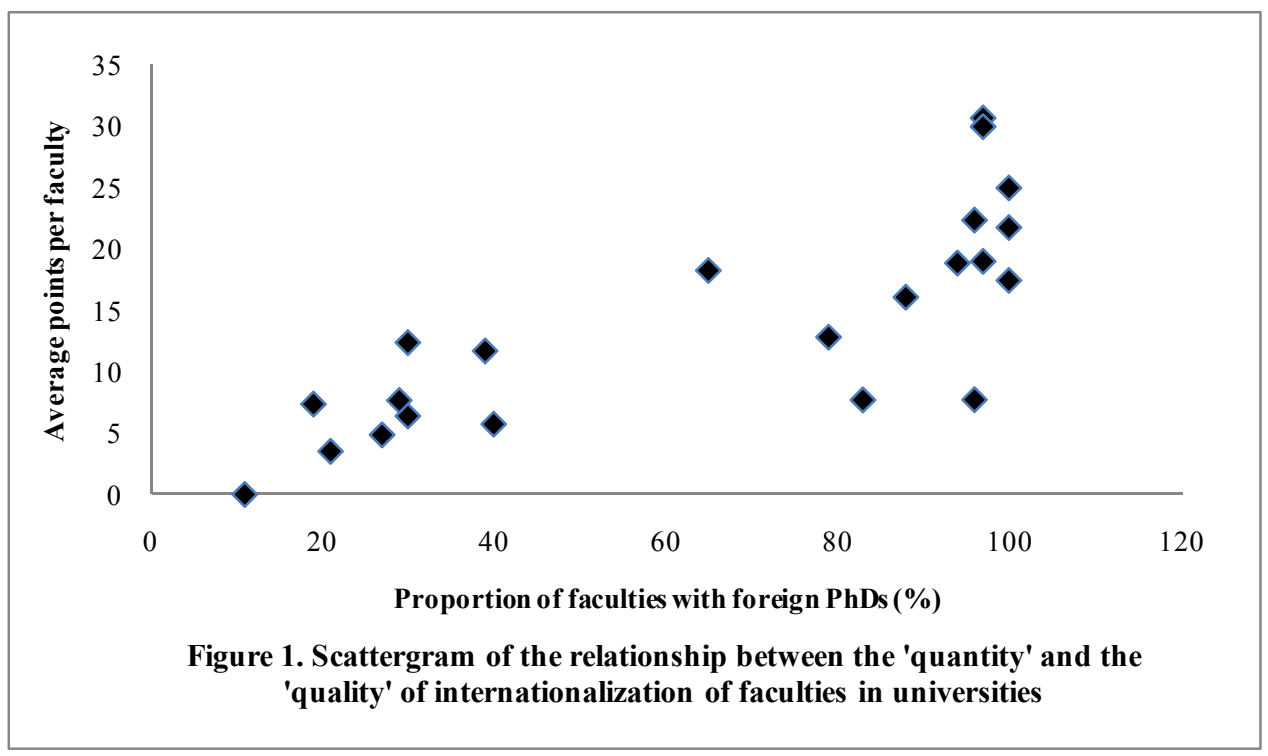

\section{Conclusions}

This study examined the 'quantity' and 'quality' of internationalisation of the faculties in the top universities in China, Hong Kong, Japan, Singapore and South Korea. Then, it was disclosed that the top universities in Hong Kong, Singapore and South Korea are at the forefront of Asian universities in terms of both 'quantity' and 'quality'. On the contrary, the top Chinese and Japanese universities are poorly internationalized in both senses.

Though Chinese economy or its Gross Domestic Product (GDP) has currently surpassed Japan's economy or GDP, Japan has been still far richer than China in terms of GDP per capita. Indeed, in 2001, China's GDP per capita was 6 071.47 (USD) but that of Japan was 46706.72 (USD). It can be expected that the top Chinese universities will be better internationalized as China's economy grows more, which enables its students to obtain PhDs from the world's best institutes and financially allows the Chinese universities to employ faculties who hold PhDs from the global best universities (see Altbach, 2004).

In contrast, the prospect of the Japanese universities seems gloomy. Though Japan is one of the wealthiest countries in the world in terms of both GDP and GDP per capita and it can thus afford to send its students to the world's best universities and employ faculties who hold PhDs from them, the faculties in the top Japanese universities have been poorly internationalized in terms of both 'quantity' and 'quality'. It is, however, true that some of the most prestigious Japanese universities, such as Tokyo and Kyoto, have still kept the highest levels of research in a wide range of disciplines in Asia (Schwarz, 2013). Indeed, Tokyo has been top in Asia in terms of the paper production indicator (Ince, 2012). Thus, it can be argued that internationalization of faculties in Japan is less necessary than other Asian countries because faculties of Japanese universities may be 'superior' even though they generally hold Japanese PhDs.

Excellence in research by the faculties in the top Japanese universities should not be neglected, but it should not be at the same time forgotten that their high-quality research may owe much to the wealth of Japan (Russel International Excellence Group, 2010). As mentioned above, China, the biggest economy in Asia in size, has been still thoroughly beaten by Japan in terms of GDP per capita. Further, though Singapore's GDP per capita is highest in Asia, its economy in size (276.52, billion USD) is far smaller than that of Japan (5 960.27, billion USD). Thus, Japan must be still the wealthiest country in Asia.

However, as the economy of South Korea, Hong Kong and China is expected to grow rapidly and remarkably, their economy will catch up with that of Japan in the near future, and funding levels of their universities will be increased too (see Altbach, 2004). When the time comes, it may be doubtful that Japanese universities filled with faculties, most of who hold PhDs from Japanese universities, can beat other top universities in China, Hong Kong, Singapore and South Korea, most of whose faculties are or expected to be holders of PhDs from the world's best institutes, in terms of the research levels or paper production. It must be arrogant to think that faculties who hold Japanese PhDs 
are always 'superior' though their PhD-granting institutes are not recognized as the world's best. Internationalization of faculties with high 'quantity' and 'quality' must be essential to attract international students and generate world-class research.

\section{References}

Altbach, P. G. (2004). The Costs and Benefits of World-Class Universities. Academe, 90, No. 1, 20-23. http://dx.doi.org/10.2307/40252583

Dill, D. D., \& Soo, M. (2004). Is There a Global Definition of Academic Quality? A Cross-National Analysis of University Ranking Systems. Public Policy For Academic Quality, January 2004. Retrieved from http://www.unc.edu/ppaq/docs/LeagueTables2004.pdf

Hauke, J., \& Kossowski, T. (2011). Comparison of values of Pearson's and Spearman's correlation coefficients on the same sets of data. Questiones geographicae, 30 (2), 87-93.

Ince, M. (2012). Japanese Universities Lose Ground in Asia Rankings. Retrieved from http://www.topuniversities.com/university-rankings-articles/asian-university-rankings/japanese-universities-lose -ground-asia-rankings

Knight, J. (2003). Updating the definition of internationalization. International Higher Education, 33, Fall 2003. Retrieved from http://www.bc.edu/content/dam/files/research_sites/cihe/pdf/IHEpdfs/ihe33.pdf

Ministry of Education, Culture, Sports, Science and Technology, Japan. (2008). 2008 White Paper on Education, Culture, Science and Technology. Retrieved from http://www.mext.go.jp/b_menu/hakusho/html/hpab200801/1292564.htm

Morrs, B. J. (2009). Internationalizing the University: Theory, Practice, Organization and Execution. Journal of Emerging Knowledge on Emerging Markets, 1, Issue 1, November 2009. Retrieved from http://digitalcommons.kennesaw.edu/cgi/viewcontent.cgi?article=1011\&context=jekem

Russel International Excellence Group. (2010). The challenge of sustaining world-class higher education in the UK. Russel Group Papers, 2, 2010.

Salmi, Jalmi. (2009). The Challenge of Establishing World-Class Universities. Washington, DC: World Bank. http://dx.doi.org/10.1596/978-0-8213-7865-6

Schwalz, E. (2013). Universities in Asia: At the Heart of the Asian Century. Retrieved from http://www.topuniversities.com/university-rankings-articles/asian-university-rankings/universities-asia-heart-asi an-century

Simmons, A. T. (2014, March 11). Multicultural education \& Internationalization: Merging the Two Minds. Retrieved from https://www.nafsa.org/uploadedFiles/NAFSA_Home/NAFSA_Regions/Region_VI/States/Multi cultural\%20and\%20International\%20Education.pdf

Top Universities. (2011, August 5). Rating Universities on Internationalization: QS Stars. Retrieved from $\mathrm{http} / /$ www.topuniversities.com/qs-stars/rating-universities-internationalization-qs-stars

Yan Zhang, C. (2013). The Rise of Glocal Education: ASEAN Countries. Retrieved from $\mathrm{http} / / /$ www.topuniversities.com/where-to-study/region/asia/rise-glocal-education-asean-countries

\section{Notes}

Note 1. http://www.topuniversities.com/university-rankings/world-university-rankings/2013

Note 2. http://www.topuniversities.com/university-rankings/asian-university-rankings/2013

Note 3. http://www.topuniversities.com/university-rankings/asian-university-rankings/2011

Note 4. http://www.webometrics.info/en/node/54

Note 5. http://www.topuniversities.com/university-rankings/university-subject-rankings/2013/accounting

Note 6. http://www.topuniversities.com/university-rankings/university-subject-rankings/2013/agriculture-forestry

Note 7. http://www.topuniversities.com/university-rankings/university-subject-rankings/2011/economics-and-econo metrics 